University of San Diego

Digital USD

Spring 5-27-2017

\title{
Guidleine Implementation for Dermal Filler Administration Via \\ Blunt-tip Cannula to Decrease Post-Procedure Hematoma Formation
}

\author{
Tony Rosales \\ University of San Diego, trosales@sandiego.edu \\ Karen Sue Hoyt \\ University of San Diego, hoyt@sandego.edu \\ John W. Love \\ Before-N-After, LLC, jwlove1@gmail.com
}

Follow this and additional works at: https://digital.sandiego.edu/dnp

Part of the Nursing Commons

\section{Digital USD Citation}

Rosales, Tony; Hoyt, Karen Sue; and Love, John W., "Guidleine Implementation for Dermal Filler Administration Via Blunt-tip Cannula to Decrease Post-Procedure Hematoma Formation" (2017). Doctor of Nursing Practice Final Manuscripts. 40.

https://digital.sandiego.edu/dnp/40

This Doctor of Nursing Practice Final Manuscript is brought to you for free and open access by the Theses and Dissertations at Digital USD. It has been accepted for inclusion in Doctor of Nursing Practice Final Manuscripts by an authorized administrator of Digital USD. For more information, please contact digital@sandiego.edu. 


\section{Acknowledgements}

I would like to express my sincere gratitude to the entire faculty at the University of San Diego Hahn School of Nursing and Health Science: Beyster Institute for Nursing Research for their support during my program. Specifically, I would like to thank my faculty chair, Dr. Karen Sue Hoyt. Dr. Hoyt's support and mentorship was key to my pursuance and completion of my doctorate degree and I am thankful for all that she has done to help me as a student and a fellow advanced practice nurse.

I would also like to thank my seminar faculty, Dr. Gabriella Malagon-Maldonado and Dr. Tanna Thomason whose help and support was pivotal in my progression through the program. Lastly, I would like to thank Dr. Karen Macauley who seamlessly assumed the position of program director. Through her vision and leadership, the graduate program will continue as one of the finest programs in the country.

Completion of this project could not have been accomplished without the support of Before-N-After staff. The staff helped me conceptualize, organize and implement the project. I would also like to thank Dr. John Love, M.D., medical director and co-owner of Before-N-After. Dr. Love served as my clinical mentor and project champion. With his guidance, the project was able to demonstrate a better practice technique through utilization of evidence based practice and clinical prowess.

Lastly, I would like to thank my family for believing in me and supporting me through my struggles while celebrating with me through my accomplishments. To my children, Ashley, Anthony and Alexander, thank you for being my motivation and for encouraging me to reach for my goals. I hope that I can be your inspiration. 


\section{Background}

Totaling more than 2.1 million treatments in 2015 , dermal filler treatments of hyaluronic acids (HAs) are the second most common in-office cosmetic procedure performed in the United States (van Loghem, Humzah, \& Kerscher, 2016). In an attempt to minimize dermal filler complications, blunt-tipped cannulas have emerged as an alternative technique to the use of 27-gauge needle administration. Because blunt-tipped cannulas navigate through the dermis without the sharp tip of a needle, cannulas are believed to cause less pain and bruising in addition to less risk of arterial embolization (AE) (Ozturk et al., 2013).

Intra-procedural pain and extended post procedure recovery due to bruising are dermal filler complications that negatively impact patient overall experience (Brandt, Bank, Cross, \& Weiss, 2010). Therefore, techniques to limit these complications are important in a competitive consumer based medical model such as that seen in a med-spa. The ability to offer potential clients a less painful technique, with less bruising and less risk of arterial embolization is a significant competitive advantage. A Southern California medical practice with three facilities and five aesthetic providers was selected as the site for an evidence based project to evaluate a best practice technique.

\section{Introduction to the Evidence}

A review of the literature was conducted via electronic searches through an institution library. Databases searched included PubMed, Cochrane and CINAHL. Articles were synthesized and evaluated based on relevancy, applicability to practice setting, level of evidence and publication date. When utilizing similar aesthetic technique, both cannula and needle have been shown to provide equal aesthetic 
improvement with less pain and bruising as compared to needle administration (Fulton, Caperton, Weinkle \& Dewandre, 2012). A study of cadaver heads evaluating placement of HAs by both cannula and needle demonstrated a more precise placement with cannula use and intra-arterial injection with needle (van Loghem, Humzah, \& Kerscher 2016). Although no specific clinical trials or studies have demonstrated cannula use completely prevents AE, cannula use is recommended to decrease AE events (Yeh, Fabi, \& Welsh, 2017). Additional techniques shown to decrease pain, bruising and AE include aspiration before injection, retrograde injection, slow speed of injection, and reduced ejection force (Glogau \& Kane, 2008). However, it is important to note that Yeh, Fabi and Welsh (2017), reported two cases of AE occurred while using a blunt-tipped cannula.

In a 2012 article by Lazzeri et al., serious complications arising from AE were explored. Of the 32 cases reviewed, 29 documented cases of blindness followed dermal filler administration were attributed to AE. Complication rates of AE from dermal fillers are unclear, but a 2011 estimate reported a $0.0001 \%$ risk of AE with the glabella, nose and nasal labial folds as the areas most frequently affected (Ozturk et al., 2013). Although dermal filler administration is a relatively low risk procedure, research highlights that provider technique and knowledge of anatomy are important factors in decreasing the risk of AE (van Loghem, Humzah \& Kerscher, 2016).

\section{Methods}

Comparing intra-procedural pain and post-procedural bruising in patients receiving dermal filler administration for mid and lower face volumization was established as the project purposed. A six-week time period was identified and 24 female patients presenting for volumization of the mid and lower face were enrolled in the 
project. Patient demographics to include age, number of previous dermal filler treatments and history of aspirin product within 48 hours of the treatment was collected (see Table 1).

Table 1. Sample Demographics

\begin{tabular}{|l|c|c|}
\hline Table: 1 & $\begin{array}{c}\text { Age Range } \\
\text { (years) }\end{array}$ & Total (n) \\
\hline & $21-35$ & 3 \\
\hline & $36-50$ & 11 \\
\hline Average Age (years) & $51-65$ & 10 \\
\hline $\begin{array}{l}\text { Aspirin taken within 48 } \\
\text { hours (n) }\end{array}$ & 47 & \\
\hline $\begin{array}{l}\text { Average number of } \\
\text { previous HA treatments }\end{array}$ & 1.29 & \\
\hline
\end{tabular}

The face was divided into four treatment quadrants with all treatments being initiated in the right upper quadrant. Subsequent treatments followed a clockwise pattern until the right lower quadrant was reached (see figure 1).

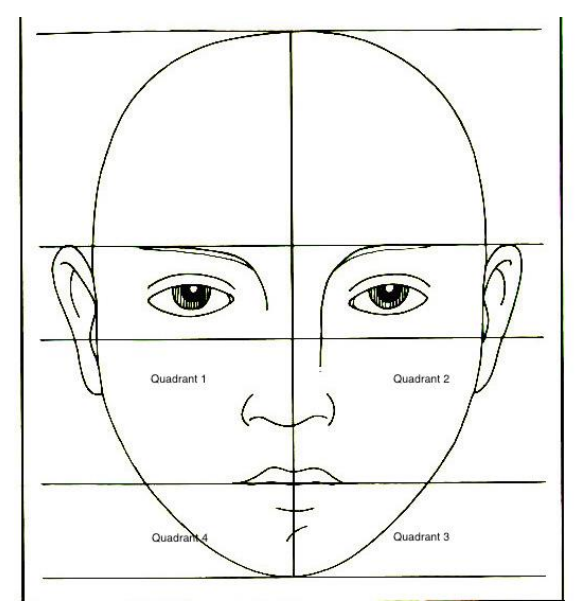

Figure 1. Four Facial Quadrants 
Patients were administered a total of two milliliters (ml) of hyaluronic acid, one $\mathrm{ml}$ per side for treatment of the mid and lower face. Each patient had one side of their face randomized and treated with a 27-gauge, 1-inch blunt-tip cannula and the other side treated via the pre-packaged 27-gauge 1-inch needle. 1 milliliter of hyaluronic acid was administered to each side and the same injector performed all treatments after pretreating the area with a topical anesthetic.

Upon the completion of treatment for each quadrant, participants were asked to rate their pain on a Likert-type scale that ranges from 0 to 10 . Participants were instructed that a rating of 10 equals intense pain and a rating of 0 equals no pain. All patients received discharge instructions not to massage the area and to return in 2 days. Upon return to the clinic, patients were interviewed regarding their adherence to the discharge instructions given to them at the previous visit. If bruising was assessed, bruising for each quadrant was recorded in millimeters. 


\section{Results}

The average diameter for bruising with cannula administration was $0.43 \mathrm{~mm}$ in comparison to $1.68 \mathrm{~mm}$ with needle administration and was statistically significant $(\mathrm{p}<$ 0.01) (see figure 2). When bruising present, bruising with cannula use was less in all four quadrants in comparison to needle.

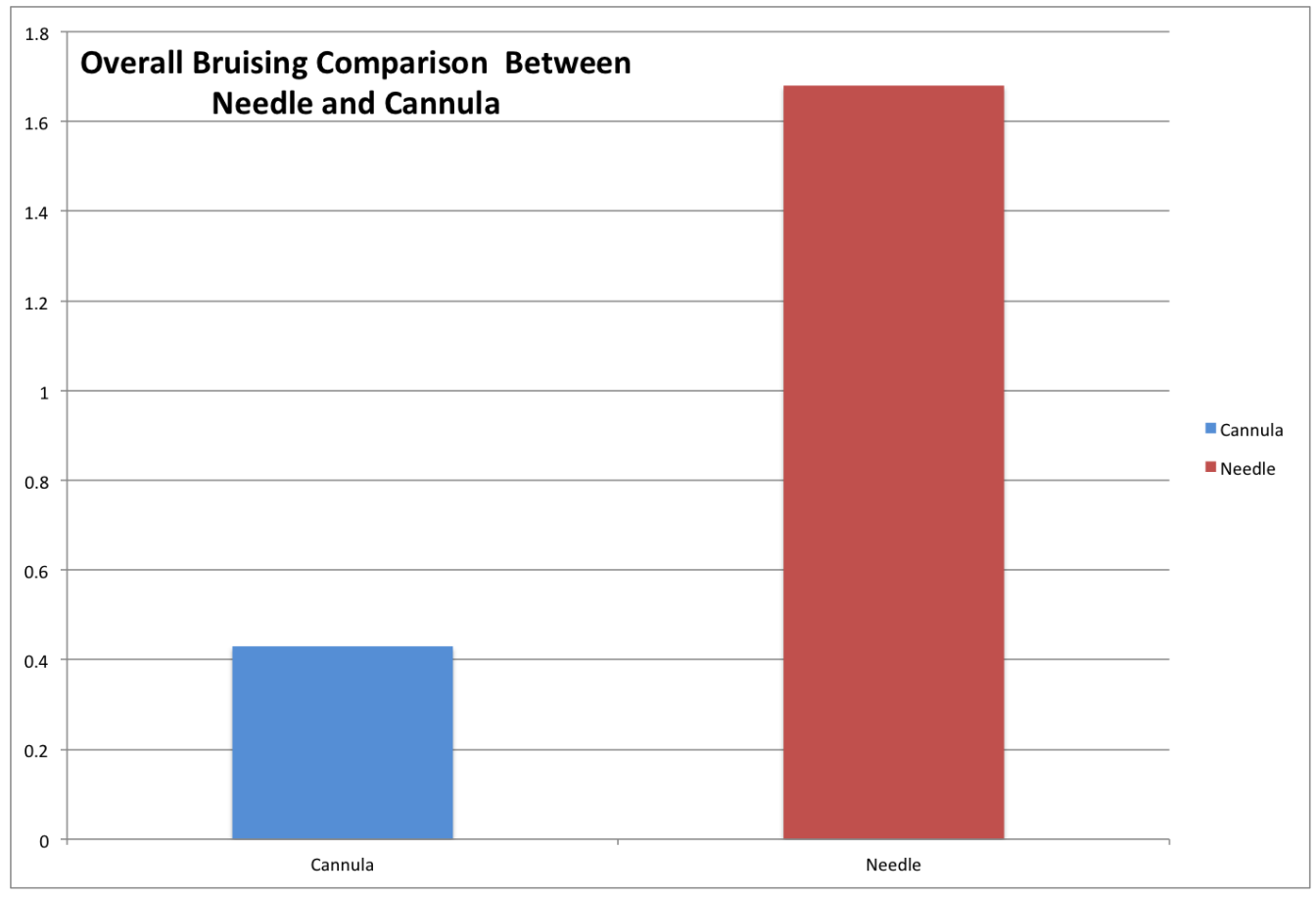

Figure 2. Overall Bruising Comparison between Needle and Cannula

Pain was also less in cannula administration with overall pain rated as 1.93 as compared to 3.18 with needle administration $(\mathrm{p}<0.01)$ (see figure 3$)$. In support of the evidence, cannula use also resulted in less pain in all four quadrants in comparison to pain. 


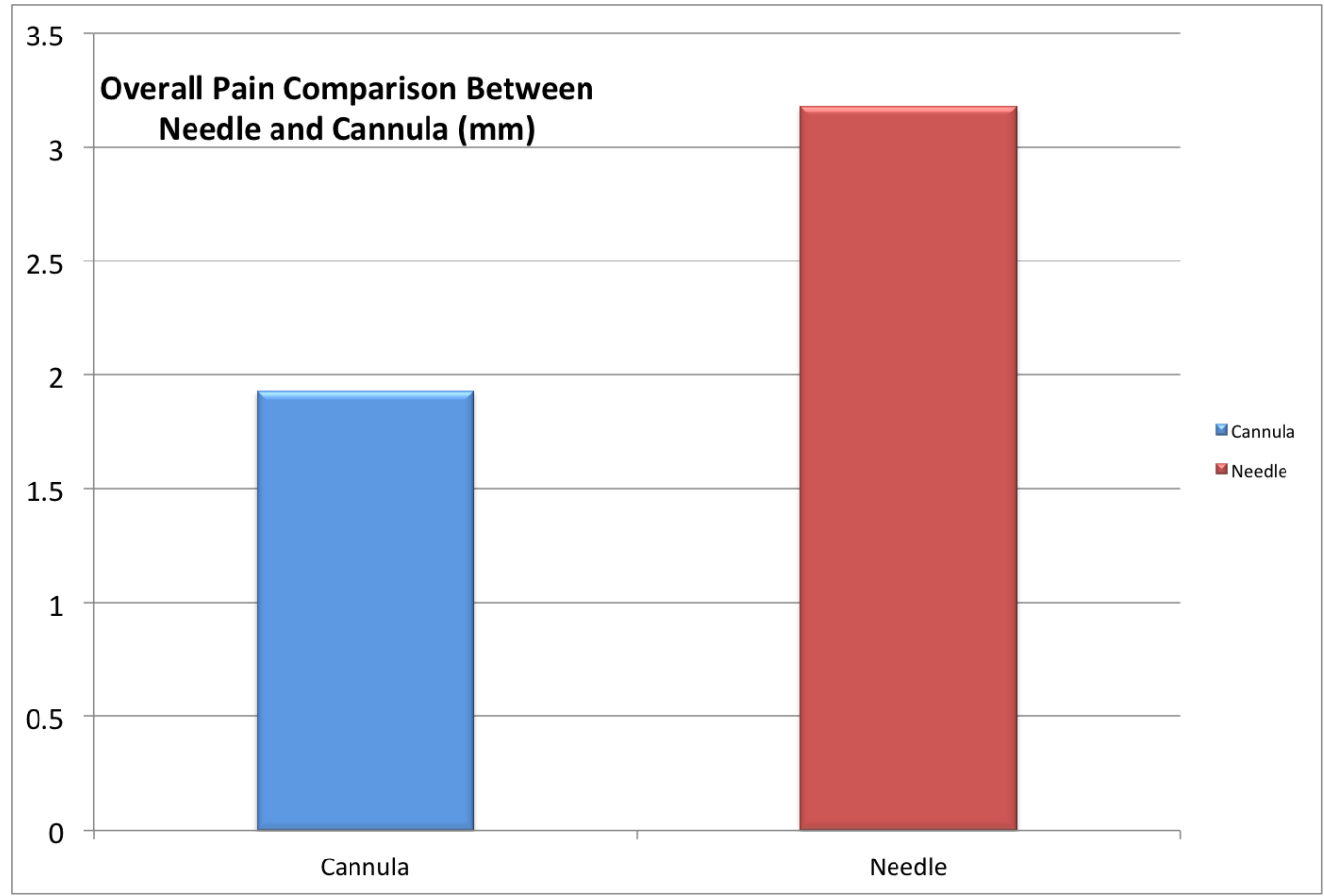

Figure 3. Overall Pain on Likert Scale from 0 to 10

Cannula use not only resulted in overall less pain and bruising, when bruising was present, bruising from needles averaged $3.12 \mathrm{~mm}$ as compared to only $2.5 \mathrm{~mm}$ with cannula. Additionally, bruising was not present in $83 \%$ of areas treated with cannula in comparison to only $45 \%$ for areas treated with a needle.

\section{Costs Savings}

The total additional cost associated with the EBP implementation was $\$ 150.00$. EBP costs consisted of $\$ 6.00$ per cannula and one 30-minute training session for five non-medical staff. Other than the additional material cost of purchasing one $\$ 6.00$ cannula per patient, inclusion of cannulas does not have cause the practice to incur any additional fixed costs. However, in order to provide more information on the advantages of cannula technique to the clinics market base, additional marketing tools to include website modification, magazines, email campaigns, and in-clinic advertising flyers will need to be considered. 
In contrast to the relatively low product cost, cannula use has significant potential for business growth. EBP findings support decreased pain and hematoma formation when using cannula. As a result, patients receiving dermal fillers via cannula technique would be more likely to have an improved overall experience from those who received dermal fillers via needle. Considering that aesthetic medicine is a consumer-based practice model, the blunt-tipped cannula technique would help increase practice revenue due to improved patient experience

\section{Implications for Practice}

An important secondary gain of blunt-tipped use would be the potential decrease in arterial embolization (Hexsel et al., 2012). Van Loghem, Humzah, and Kerscher (2016) suggest that the smooth tip of the cannula may protect patients against inadvertent injection of hyaluronic acid within the artery. Because the smooth tip of the cannula cannot puncture the vessel wall, the cannula navigates through the dermis, pushing soft tissue structures such as blood vessels out of the way. Although the authors admit that the risk of embolization still occurs, it is suggested that the risk is significantly less with cannula use. Additional research in arterial embolization from cosmetic procedures is needed to fully understand the risk that patients take with dermal fillers.

\section{Sustainability}

Sustainability of the project will be challenged by tendencies for providers to resort back to familiar injection techniques utilizing a needle. Additional challenges are expected due to the material costs of purchasing cannulas. However, after considering the decreased risk of $\mathrm{AE}$ and increased business growth, sustainability should be a priority for both the clinician and the organization as a whole. 
A decrease risk in hematoma formation and potential embolization of facial arteries provide a safer environment for the aesthetic provider to practice and this idea will need to be reinforced by the lead DNP for the practice. It is expected that patient's preference for treatments that result in decreased pain and bruising will also help sustainability. Ultimately, the facility will be responsible for practice guidelines updates and enforcement.

\section{Limitations}

Sample size for the EBP was relatively small. It is recommended that a longer time frame, or period of time with higher volume be considered for future projects. Additional limitations to the project included a lack of male patients, and few patients with no history of previous dermal fillers. Research into cool packs and their affect on bruising was not established as well as a bruising tool with established reliability and validity was not utilized. However, a literature review failed to locate a standardized bruising tool for the assessment of bruising post cosmetic facial procedure. 


\section{References}

Brandt, F., Bank, D., Cross, S., \& Weiss, R. (2010). A lidocaine-containing formulation of large-gel particle hyaluronic acid alleviates pain. Dermatologic Surgery, 36(S3), 1876-1885. http://dx.doi.org/10.1111/j.1524-4725.2010.01777x

Fulton, J., Caperton, C., Weinkle, S., \& Dewandre, L. (2012, September 2012). Filler Injections with blunt-tip microcannula. Journal of Drugs in Dermatology, 11(9), 1098-1103. Retrieved from PMID:23135654

Glogau, R., \& Kane, M. (2008, June 2008). Effect of injection techniques on the rate of local adverse events in patients with nonanimal hyaluronic acid gel dermal fillers. Dermatology Surgery, 34(), S105-S109. http://dx.doi.org/10.1111/j.15244725.2008.34251.x

Hexsel, D., Soirefmann, M., Porto, M. D., Siega, C., Schilling-Souza, J., \& Brum, C. (2012). Double-blind, randomized, controlled clinical trial to compare safety and efficacy of a metallic cannula with that of a standard needle for soft tissue augmentation of the nasolabial folds. Dermatologic Surgery, 38(), 207-214. http://dx.doi.org/10.1111/j.1524-4725.2011.02195.x

Lazzeri, D., Agostini, T., Figus, M., Nardi, M., Pantaloni, M., \& Lazzeri, S. (2012, April 2012). Blindness following Cosmetic Injections of the Face []. Plastic and Reconstructive Surgery, 129(4), 995-1012. http://dx.doi.org/10.1097/PRS.0b013e3182442363

Merianos, A. L., Vidourek, R. A., \& King, K. A. (2013). Medicalization of Female Beauty: A Content Analysis of Cosmetic Procedures. The Qualitative Report, 
18(91), 1-14.

http://dx.doi.org/http://www.nova.edu./ssss/QR/QR18/merianos91.pdf

Ozturk, C. N., Li, Y., Tung, R., Parker, L., Piliang, M. P., \& Zins, J. E. (2013).

Complications Following Injection of Soft-Tissue Fillers. Aesthetic Surgery Journal, 33(6), 862-877.

Van Loghem, J. A., Humzah, D., \& Kerscher, M. (2016, December 2016). Cannula

Versus Needle Placement of Soft Tissue Fillers: An Observational Cadaver Study.

Aesthetic Surgery Journal, 1-16. http://dx.doi.org/10.1093/asj/sjw220

Yeh, L. C., Fabi, S. G., \& Welsh, K. (2017). Arterial Penetration With Blunt-Tipped

Cannulas Using Injectables: A False Sense of Safety? Dermatologic Surgery, 43(3), 464-466. http://dx.doi.org/10.1097/DSS.0000000000000929 


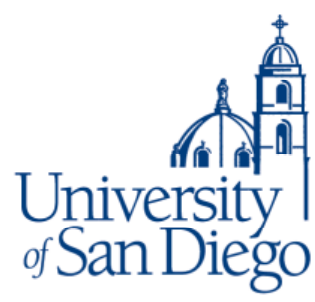

\section{Institutional Review Board Project Action Summary}

Action Date: June 24, 2016

Note: Approval expires one year after this date.

Type: __ New Full Review __ New Expedited Review __ Continuation Review_X_Exempt Review Modification

Action:

X_Approved

Approved Pending Modification

Not Approved

Project Number:

Researcher(s):

2016-06 -247

Tony Rosales DNP student SON

Dr. Sue Hoyt Fac SON

Project Title: Conversion from needles to blunt-tipped cannulas for administration of dermal fillers in patients requesting mid-face augmentation

Note: We send IRB correspondence regarding student research to the faculty advisor, who bears the ultimate responsibility for the conduct of the research. We request that the faculty advisor share this correspondence with the student researcher.

\section{Modifications Required or Reasons for Non-Approval}

None

The next deadline for submitting project proposals to the Provost's Office for full review is N/A. You may submit a project proposal for expedited review at any time.

Dr. Thomas R. Herrinton

Administrator, Institutional Review Board

University of San Diego

herrinton@sandiego.edu

5998 Alcalá Park

San Diego, California 92110-2492

Office of the Executive Vice President and Provost

Hughes Administration Center, Room 214

5998 Alcalá Park, San Diego, CA 92110-2492

Phone (619) 260-4553 • Fax (619) 260-2210 • www.sandiego.edu 